PEER MENTORING IN TEACHING ASSISTANTS

\title{
Reframing Peer Mentoring as a Route for Developing an Educational Community of Practice
}

Laura J. Nicholson $^{a}$, Sara Rodriguez-Cuadrado ${ }^{b}$ and Clare Woolhouse ${ }^{a}$

${ }^{a}$ Faculty of Education, Edge Hill University, Ormskirk, Lancashire, UK

${ }^{b}$ Department of Psychology, Edge Hill University, Ormskirk, Lancashire, UK

Corresponding author: Laura J. Nicholson, Faculty of Education, Edge Hill University, Ormskirk, L39 4QP, UK. Email: Laura.nicholson@edgehill.ac.uk. Tel: 01695 657277, Fax: 01695579997

Dr Laura J. Nicholson is a Research Associate in the Faculty of Education at Edge Hill University. Her research interests focus on student engagement, including the factors that influence and are influenced by it, and attitudes towards learning in a variety of contexts.

Dr Sara Rodriguez-Cuadrado is a Lecturer in the Department of Psychology at Edge Hill University. Her research interests encompass language, perception and learning disabilities.

Dr Clare Woolhouse is a Senior Research Fellow in the Faculty of Education at Edge Hill University. She has worked on a number of funded research projects relating to the professional development of those in the school workforce, with a particular focus on the area of primary school interventions, inclusive practice and SEN education. Her research interests revolve around identity formation, particularly gendered identity, equality, diversity and inclusion. 


\title{
Reframing Peer Mentoring as a Route for Developing an Educational Community of
}

\section{Practice}

\begin{abstract}
The benefits of peer mentoring in school settings are well-documented, however, the focus has been on the perceptions of teachers, as opposed to teaching assistants (TAs), who report distinct beliefs about their professional development. A mixed methodology was used in which 304 primary school TAs completed questionnaires regarding their views of their professional development while undertaking training on a mathematics intervention for underachieving pupils. Open-ended questions elicited the perceived benefits of the peer mentoring aspect of the training. We utilized Lave and Wenger's (1991) community of practice framework to inform the qualitative analysis and the principles of grounded theory to arrive at three themes representing the perceived benefits: an opportunity to discuss and share experiences; increased confidence; and a safe space to test teaching plans and resources. Findings were used to reframe the benefits of peer mentoring for TAs undertaking intervention training, which can inform further research and future training programs.
\end{abstract} Keywords: peer mentoring, teaching assistants, communities of practice, intervention training

The views of teaching assistants (TAs), who were undertaking training in a mathematics intervention for primary school pupils, regarding the benefits of the face-to-face sessions and peer mentoring aspects of the training, were explored, in this evaluative study. Although there is some, albeit limited, research on the impact of intervention training on teachers' professional development (e.g., Torgerson et al., 2011), we were unable to find any literature on these effects for TAs, whose experiences, beliefs and concerns are distinct from those of teachers (Dunne, Goddard, \& Woolhouse, 2008a, 2008b). It is important to determine how face-to-face training, and in particular, peer mentoring, is perceived to be 
advantageous to TAs, in order to both inform the literature on peer mentoring in this context and to guide the design of future intervention training programs. A range of benefits of peer mentoring have been reported in the literature (e.g., Buzbee Little, 2005; Rhodes \& Beneicke, 2002), although, the research conducted in the school setting have again focused on the perceptions of teachers. In the present study, we elicited the views of TAs using a mixed methodology. We engaged with Lave and Wenger's (1991) conceptualization of a 'community of practice', as a group of individuals who share similarities in, for example, geographical location, purpose and/or role. In doing so, we identify TAs as individuals who form an educational community of practice due to similarity of role (i.e., TAs training to be intervention specialists) and use this idea to provide a theoretical framework in which to analyze how they perceived the benefits of peer mentoring. A grounded theory approach (Strauss \& Corbin, 1998) was then employed to reframe peer mentorship and arrive at a process of peer mentorship benefits for TAs undertaking intervention training.

We begin with some contextual information on the prevalence of mathematics underachievement in UK primary schools, the intervention programs in which the participants of the study were undertaking training, and on the role of the TA in UK schools. This is followed by details of the training the TAs received and a literature review on the effects of intervention training on the professional development of teachers. Peer mentoring is then defined and literature reviewed on the benefits of peer mentoring in school settings. Full details of the method, findings and discussion, and conclusion follow.

\section{Background}

Despite the importance for young children to be able to "count, calculate and work confidently with mathematical ideas" (Williams, 2008, p. 3), 7\% of pupils failed to achieve the expected national curriculum level at the end of key stage 1 (Year 2) and 13\% did not reach the expectation in key stage 2 (Year 6) in mathematics in 2015 (Department for 
Education, 2015a, 2015b). This highlights the need for interventions in primary school to improve mathematical attainment. The Every Child Counts (ECC) program started in 2008 as an initiative from the Education Ministry in England. Its aim was to intervene into mathematical underachievement (Every Child a Chance Trust, 2010). The main intervention program was Numbers Count (NC), which was designed to help get back on track the 30,000 lowest achieving children in Year 2 (i.e., aged 6-7 years old, Dowrick, 2015). NC, which is still being taught and used today, is delivered by specially trained teachers to children who find mathematics extremely difficult. Following the success of the original NC program, several other ECC interventions were developed, two of which, 1stClass@ Number (1CN) and 1stClass@ Number2 (1CN2), are the focus of the current research. These interventions were designed for pupils who had fallen behind in mathematics, but whose difficulties were milder than those considered for NC. Typically, $1 \mathrm{CN}$ is delivered to Year 2 pupils (aged 6-7 years) and 1CN2 to children in Years 3 and 4 (aged 7-9 years). Both interventions are delivered by trained TAs to small groups of children (normally four pupils).

The TA role in UK primary schools has become crystalized over the past 15 years as the UK Government's agenda around educational workforce 'remodeling' (Department for Education and Skills, 2003) has taken shape. The number of TAs has increased three-fold over this period, and they now comprise $28 \%$ of the education workforce (Department for Education, 2016). TAs are employed to support teaching and learning within classrooms working alongside teachers, and their role has evolved from completing tasks such as laminating and washing paint pots to providing instruction, managing behavior, designing curriculum, and providing individual support for a child or a small group of children with additional learning needs (Blatchford, Russell, Bassett, Brown, \& Martin, 2007; Chambers, 2015). Their deployment has eased the burdens on teachers created by the minimization of schools with provision for pupils with special educational needs and disabilities, and the drive 
towards mainstream education for the majority of children. However, despite the fact that TAs work with children who need more support, they tend to be the group of educational professionals who receive the least training and who's practices and views are undervalued (Chambers, 2015; Dunne et al., 2008a, 2008b; Woolhouse, Dunne, \& Goddard, 2009). In this evaluative study, we aimed to provide a platform for the experiences of TAs to be shared more widely.

\section{Intervention Training}

A thorough and extensive professional development program to inform and support the delivery of the interventions underpins the training (Dowrick, 2015). While undertaking the $1 \mathrm{CN}$ interventions, TAs receive six half-days of training in their first term, two half-day follow-up sessions in the subsequent term, and are supported by a Link (NC) Teacher throughout. Similar to the NC interventions, there is a focus on developing a "collaborative learning culture" (Dowrick, 2015, p. 26). Every training meeting begins with a "Review, Evaluate, Discuss, and Share" session in which the participants talk about their experiences of working with the children (N. Dowrick, personal communication, May 9, 2017). This sharing is devised to encourage peer collaboration in order that professionals can work together to devise solutions to common problems.

Clearly, the objective of mathematics interventions is to benefit the pupils in terms of their mathematics attainment and this has been demonstrated elsewhere (for instance, see Torgerson, Wiggins, Torgerson, Ainsworth, \& Hewitt, 2013). Despite the range of mathematical intervention programs that have been designed (see Dowker, 2004), limited research has specifically addressed the effects of the intervention training on the individuals undertaking the programs. One exception is a study of teachers undertaking training on the Primary Maths specialist program (Kutaka et al., 2017). The teachers reported that their peer relationships were key to their learning and engagement with the training, and prevented 
them from feeling alone. Their motivation and knowledge for mathematics were higher than those of a control group, and they reported less anxiety. Moreover, Torgerson et al. (2011) conducted observations, interviews and surveys with the teachers undertaking the NC interventions and concluded that they were positive about their professional development, and considered the most valuable aspect of the training to be "discussion between colleagues during these sessions, facilitated by the experience that the trainer brought to the sessions" (p. 93). Of the 242 teachers surveyed, $95 \%$ valued the opportunity to discuss practice with colleagues, reporting that this facilitated learning, enabled them to share ideas and discuss problems, and provided an opportunity to reflect on their practice. Also, $87 \%$ of the teachers appreciated the support and visits they received from their mentors on the program, and $84 \%$ endorsed the focus on understanding the mathematics curriculum.

It is an empirical question whether the positivity reported by the NC teachers is similarly perceived by the TAs undertaking the $1 \mathrm{CN}$ training. As both $\mathrm{NC}$ and $1 \mathrm{CN}$ were designed by the ECC team, many aspects of the training overlapped. There were differences, however, in the amount of training the professionals received on each program (seven days for $\mathrm{NC}$ versus eight half-days for $1 \mathrm{CN}$ ), and importantly, only qualified teachers could train on the NC programs, but the $1 \mathrm{CN}$ interventions were designed to be delivered by TAs. TAs were traditionally deployed to support pupils with reading and other difficulties, rather than those with mathematical difficulties (Dowker, 2004; Muijs \& Reynolds, 2003), although there have been several mathematical interventions which have been designed specifically to be delivered by TAs (e.g., Catch Up Numeracy, Dowker \& Sigley, 2010), in part because it is difficult to release class teachers for training and intervention delivery, and because TAs are cheaper to resource (Woolhouse et al., 2009). Regarding the effective use of TAs to deliver educational interventions, Samson, Hines and Li (2015) reported that extensive training, ongoing supervision and scripted lessons were important. Domitrovich et al. (2009) found 
that, following intervention training that included intensive mentoring, benefits to students were equal whether the intervention was delivered by a TA or lead teacher.

Although we were unable to detect any studies that focused on the effects of intervention training on the professional development of TAs, there has been some research that has examined the perceptions of TAs who had recently graduated from a foundation degree in supporting teaching and learning (a vocational degree level program). The TAs reported a range of intrinsic benefits that resulted from this professional development qualification, including increased self-confidence, self-esteem, motivation and awareness of their learning potential, as well as improved practice in the classroom (Dunne et al., 2008b). Conversely, there was also an element of disillusionment regarding their professional status and career progression (Dunne et al., 2008a, 2008b). Importantly, the TAs acknowledged the crucial role of their peers and reported that they would not have graduated without such a supportive network (Woolhouse et al., 2009). Sharing experiences and developing new ideas with TAs from other schools was a recurring benefit, suggesting that they valued collaborative learning (Dunne et al., 2008a), echoing the perceptions of the NC teachers reported earlier (Torgerson et al., 2011). The effectiveness of peer mentoring and enjoyment of a collaborative approach have also been reported by TAs studying for a credential in early childhood education (Garner, McLean, Waajid, \& Pittman, 2015). TAs may perceive peer mentoring as an opportunity to develop relationships that are less hierarchical in nature and less institutionally-constrained than those in which they are more acquainted with in their professional roles (Reid, 2008). We address the gap in the literature by exploring the views of TAs undertaking training on a mathematics intervention program. Based on previous findings, we focused on the impact of the face-to-face training sessions and peer mentoring aspects.

\section{Peer Mentoring}


As opposed to traditional mentoring, when engaged in peer mentoring, participants have a similar level of knowledge (Blase, Hekelman, \& Rowe, 2000) and develop a relationship based on equality (Zeus \& Skiffington, 2002). Peer mentoring involves a voluntary relationship between individuals who are in a similar situation (i.e., peers) and is based on a reciprocal sharing of experiences for the collective purpose of enhancing personal growth and professional development (Kaunisto, Estola, \& Niemisto, 2012; Kroll, 2017). There is a learning agreement, goals are set and conversations center around learning, complemented with a component of self-evaluation and growing self-direction, where the relationship focuses on the strengths and development of the participants (Cordingley, 2005; Schwellnus \& Carnahan, 2014). The importance is not on how frequently the parties meet, but on the continuity of the relationship, in order to explore experiences and solve issues (Williams \& Grant, 2012). Trust is an essential feature of effective peer relationships, and is determined by shared values, confidentiality and the capacity of both peers to make themselves vulnerable (Cox, 2012). Kroll (2017) concluded that the five characteristics that peers must possess for effective mentoring are an intrinsic interest, a learning disposition, a commitment to the mentoring experience, ease with vulnerability and sharing their struggles, and a desire to support others in their learning and development. In the following section, we outline some of the benefits of peer mentoring relationships.

Benefits of peer mentoring. Positive effects of peer mentoring are well-documented in a variety of contexts (e.g., Cheetham \& Chivers, 2001). In schools, research on peer mentoring has primarily been conducted with teachers. For teachers, collaboration has been found to lead to increased confidence, enhanced beliefs that they can make a difference to pupils' learning, enthusiasm for collaborative working, a greater commitment to changing practice and better learning outcomes for students (Cordingley, Bell, Rundell, \& Evans, 2003). Peer mentoring can also lead to a sense of togetherness, improved ability to cope, 
empowerment and self-reflection processes (Kaunisto, Estola, \& Leyman, 2013; Kaunisto et al., 2012). Importantly, reflecting on one's own practice is crucial for professional development (Eraut, 1994; Schön, 1983). Rhodes and Beneicke (2002) listed four benefits of peer mentoring, including that it promotes teacher empowerment by enhancing confidence and self-esteem, supports the transfer of teacher learning to pupil learning, encourages greater ownership of teachers' own professional development, and creates an atmosphere of mutual trust and respect, which is essential to enhancing performance at all levels. Buzbee Little (2005) focused on the sense of belonging fostered by peer mentoring, which she argued results in a non-threatening, comfortable working environment in which teachers feel less isolated, more empowered, more able to explore new teaching strategies and more likely to internalize professional development and success. Specifically, belonging to a "community of practice" (Lave \& Wenger, 1991) has a range of benefits, as discussed below.

\section{The Present Study}

In order to theoretically underpin this study of TAs' perceptions of peer mentoring, we engaged with Lave and Wenger's (1991) approach to how learning assists individuals to integrate into a community of practice. In their work, Lave and Wenger (1991) explored how different professionals develop a sense of professional identity as they acquire the relevant knowledge, language, skills and experience, and learn from other members of the same community how to become a full practitioner. These other members may be experienced "master practitioners" or other "apprentice" peers. Our aim was to explore the process of learning to deliver an intervention and consider how this might influence the ways professional TAs identify themselves as intervention specialists who belong to a community of intervention practitioners. The training of education professionals is not addressed within Lave and Wenger's (1991) work, but their ideas about how "learning and a sense of identity are inseparable" (p. 115) informed our analysis of the TAs' reported experiences. If, as Lave 
and Wenger contended, learning influences how someone feels about themselves and how they feel about fitting in with others in a community, then their work offers a route for exploring how TAs might negotiate ways of becoming mathematics specialists who belong to an educational community of intervention specialists.

Lave and Wenger (1991) reported that individuals display membership of a community by developing ways of "talking about and talking within practice" (p. 109). For the TAs involved in the $1 \mathrm{CN}$ programs, talking about the mathematics interventions and/or how they work with their peers in the face-to-face sessions might provide opportunities for them to develop a sense of belonging to a specific community of practice. These partnerships in learning may materialize through the ways they talk about their work and practice their teaching with each other. A sense of belonging to a community of practice benefits teachers by reducing their feelings of isolation (Hramiak, 2010), providing a support network, and helping to establish their professional identity (Kelly, Gale, Wheeler, \& Tucker, 2007).

Thus, in this research, we build on previous literature which has established that peer mentoring was highly valued by teachers regarding intervention training (Torgerson et al., 2011) and TAs regarding the completion of a foundation degree (Dunne et al., 2008a; Woolhouse et al., 2009). The main aim of the research was to extend this body of work to TAs undertaking training on the $1 \mathrm{CN}$ interventions by exploring their views regarding the benefits of face-to-face sessions and peer mentoring. We interpreted the emerging themes in relation to Lave and Wenger's (1991) community of practice framework and the existing literature, before using them to reframe peer mentorship in the current context using a grounded theory approach (Strauss \& Corbin, 1998).

\section{Method}


The current research used a mixed methodology, which was designed to collect both quantitative and qualitative data on the attitudes of the TAs in relation to their development in response to the training sessions.

\section{Participants}

As this was an evaluative study, Link Teachers were provided with questionnaires at the beginning of the academic year, 2013-14, and asked to distribute them to all available TAs on completion of their $1 \mathrm{CN}$ or 1CN2 training. During the academic year 2013-14, 840 and 1,165 individuals (typically TAs) trained on the 1CN and 1CN2 programs, respectively. As groups of TAs would have completed their intervention training during different terms, it is possible that Link Teachers did not administer the questionnaire at all of the final training sessions. Also, not all TAs would have attended their final training session and of those who did, not all would have wanted to complete the questionnaire. Sampling could therefore be described as opportunistic. A total of 304 TAs completed the questionnaire, of which 290 were female (95.4\%), 10 were male (3.3\%) and four did not provide details of their gender $(1.3 \%)$. They worked in a range of primary schools located across England, with pupils from reception (aged 4-5 years old) to Year 6 (aged 10-11 years old). Just under half of the participants were undertaking training in relation to $1 \mathrm{CN}(144,47.4 \%$; i.e., typically based in Year 2), while the slight majority attended training sessions on 1CN2 (160 participants, $52.6 \%$; i.e., typically based in Years 3 and 4$).$

\section{Measures}

In the questionnaire, participants were asked, "Looking back to the beginning of your training, to what extent do you feel you have developed in the areas listed below?". This was followed by seven quantitative items, each measured on a 4-point scale, with points representing "strongly developed", "developed somewhat", "no change" and "realize I need to develop more" (see Table 1 for items). We intended to use the quantitative data to provide 
descriptive information in this preliminary evaluative study, as opposed to conducting inferential statistics which require extensive reliability and validity tests. Despite this, we ensured the face validity of questionnaire items by asking a panel of experts to check that they measured what we had aimed to measure. Although we did not use a composite professional development score to relate to other variables, we conducted tests of internal consistency and factor structure on the seven questionnaire items to examine interrelationships. Reliability was high $(\alpha=.89)$ and principal components analysis extracted one factor with an eigenvalue greater than 1 which explained $60.45 \%$ of the data. This indicated that the TAs answered each question in a similar manner, i.e., feeling that they had developed in one area was related to their perceived development in another.

To collect qualitative data in relation to specific aspects of the training, participants were asked two open-ended questions. The item stem, "In what way(s) have you found the following aspects of the training beneficial for your practice?" was followed by, "Face-toface sessions" and "Peer support of other school staff on the training program", and space was provided for participants to respond in their own words. A panel of experts verified the face validity of these qualitative questions.

\section{Procedure}

Link Teachers administered the questionnaires to TAs at the end of their $1 \mathrm{CN}$ or 1CN2 training, during the 2013-14 academic year. Participants were informed of the purpose of the questionnaire and ethical issues (e.g., anonymity, voluntary participation, withdrawal of data), before completing a consent form and providing details of their gender, role within the school and training program. They then answered the main questions.

\section{Data Analysis}

Data analysis of the quantitative data consisted of examining frequencies of responses to each question to provide an evaluation of the extent to which participants perceived gains 
to their professional development. The qualitative data analysis was inductive, in which we allowed themes, regarding the benefits of peer mentoring, to emerge out of the data. Following the grounded theory approach, we used a process of open-, axial- and selectivecoding to arrive at the main themes (Strauss \& Corbin, 1998). The final step was to use these themes, in conjunction with the findings from previous research and the ideas from Lave and Wenger (1991), to reframe the benefits of peer mentoring (Holt \& Dunn, 2004). The use of existing literature in theory creation is consistent with the principles of grounded theory (Strauss \& Corbin, 1998).

In order to increase the trustworthiness of the data and findings, several strategies proposed by Lincoln and Guba (1985) were followed including thick description, keeping an audit trail, peer debriefing, and negative case analysis. Further, both data and investigator triangulation were used; in addition to its standalone findings, the quantitative data were also used to triangulate the qualitative data, and all three authors independently coded the data and subsequently agreed on themes, respectively. All of the themes that emerged at each stage of coding were used in our results and no new themes emerged that were not included, which indicated that data saturation had been achieved.

\section{Findings and Discussion}

\section{General Perceptions of Professional Development}

Table 1 shows the responses of the TAs to the quantitative questions about their professional development. 
Table 1

Perceived professional development of the TAs

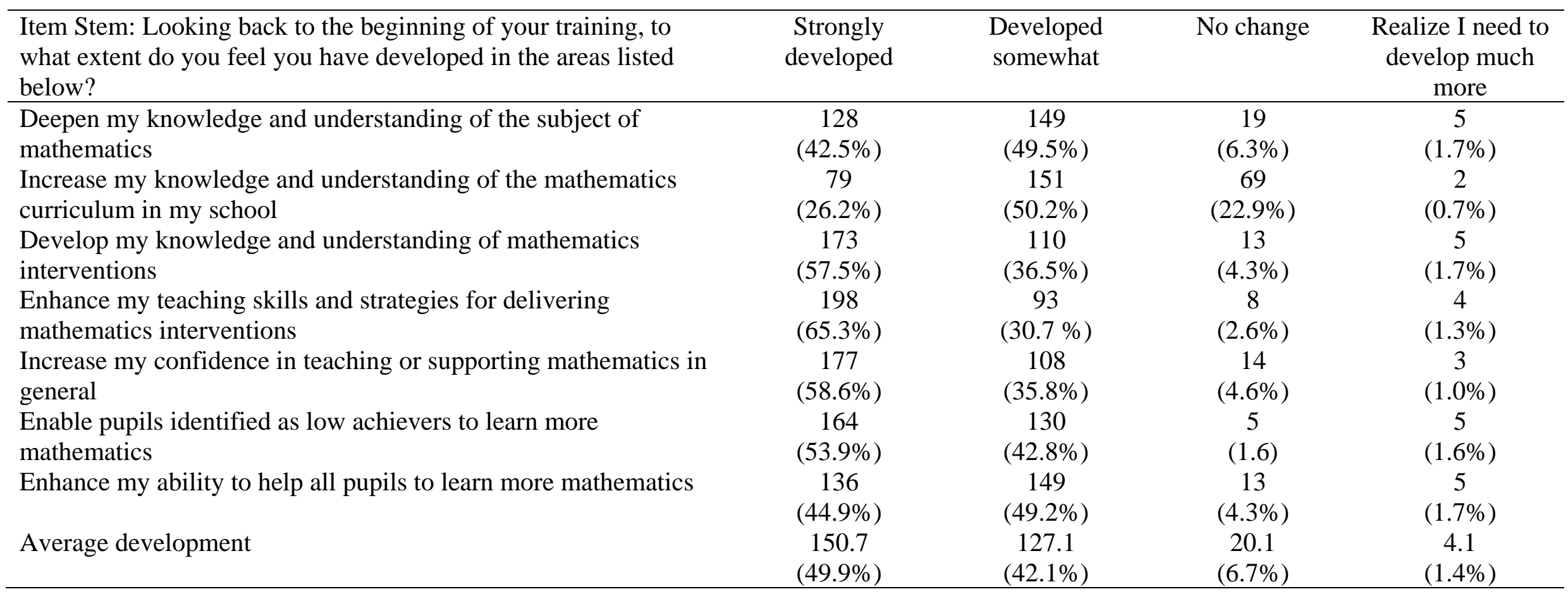


Taking all of the results for all seven items together, half of the respondents felt that they had strongly developed since undertaking their training program, and a further $42.1 \%$ believed that they had developed somewhat. The greatest perceptions of development can be seen in the participants' knowledge of, and ability to deliver, mathematical interventions, which is perhaps understandable as this was the focus of the training, and in their confidence in teaching mathematics in general. Over half of the TAs reported that they had strongly developed in their ability to teach pupils identified as low achieving. Effects on confidence and on teaching practice are discussed more fully in the results of the qualitative questions. The aspect which participants noticed the least amount of development was regarding their knowledge and understanding of the mathematics curriculum in their school, although over three quarters still acknowledged that they had developed strongly or somewhat in relation to this. Comparing this to the findings of the study by Torgerson et al. (2011), $84 \%$ of the teachers believed that developing their understanding of the mathematics curriculum was important, suggesting that this should remain as one of the objectives of the interventions.

\section{Perceived Benefits of Face-to-face Sessions and Peer Mentoring}

Out of the 304 participants, 199 responded to the question about the benefits of faceto-face contact, and 148 commented on the benefits of peer support. The reduced response rate for the latter question may be due to the participants perceiving peer support/mentoring as a prominent feature of the face-to-face training sessions, as evidenced in their comments, and so may not have felt it necessary to re-iterate their views for the second question. For this reason, responses to both open-ended questions were analyzed together.

In general, responses from the TAs who had undertaken the training were overwhelmingly positive. Comments such as, "extremely beneficial" and "very informative", were prominent in relation to both the face-to-face sessions and peer support aspect of the training. More specifically, participants mentioned that the benefits encouraged by the face- 
to-face sessions, "couldn't have been demonstrated any other way" and "helps to reinforce [learning] in memory". There were clear references to how the training programs had developed their subject knowledge, and directly improved their ability to teach and approach lessons, which supports previous research (Kutaka et al., 2017). Many participants reported how their training had been applied in the classroom, as shown in the following two quotes, Open discussions have helped with the delivery of sessions back at school (Participant $117,1 \mathrm{CN} 2)$

Being shown face-to-face how the program works has helped me to transfer the methods to the children within the group (Participant 213, 1CN2)

Benefits of the face-to-face training sessions to the pupils involved in the mathematics interventions were also mentioned, including how group discussions on how to adapt lessons for individual pupils on a step-by-step basis helped to increase the children's confidence, enjoyment and ultimately, achievement. This relates to previous research that has found that peer mentoring between teachers has positive effects on pupils (Cordingley et al., 2003; Rhodes \& Beneicke, 2002). In addition, there was evidence of the TAs cascading the new knowledge and information gained in the training sessions to colleagues external to the programs, as evidenced below,

I have been able to share my knowledge with other members of staff through staff meetings etc (Participant 216, 1CN2)

Out of all of the responses, only three negative comments were identified, one of which was a general negative comment ("not particularly beneficial') and two related to the amount of time taken for face-to-face sessions. The latter responses might reflect pressures many within the education field experience regarding the difficulties with time. In this case, time is needed to establish the trust required to facilitate close working relationships, and 
sense of belonging that is necessary to fully engage with a peer mentoring approach (Buzbee Little, 2005; Cox, 2012; Rhodes \& Beneicke, 2002).

We now turn to the focus of the paper; the perceived specific benefits of face-to-face sessions and peer support. Following a brief introduction to how the TAs perceived a supportive atmosphere on the program, the three broad themes which emerged from our analysis are discussed. The themes are: an opportunity to discuss and share experiences; increased confidence and reassurance; and a safe space to test teaching plans and resources.

A supportive atmosphere. The TAs actively spoke of a supportive atmosphere, and that they "worked collaboratively with colleagues". This was explicit in many of the comments, as demonstrated below,

Excellent peer support from my colleagues, both those on the same course and those who have previously completed it (Participant 114, 1CN2)

Support from other staff has helped me to plan and deliver the lesson better (Participant 330, 1CN)

The participants also felt supported by their "master practitioner" mentors on the program, i.e., their Link Teacher, and/or NC teacher, as illustrated below,

Link Teacher very supportive - work together to keep training on track and improve sessions (Participant 138, 1CN2)

Having Link Teacher at some training sessions made it easier to implement at school because someone to fight for importance (Participant 348, 1CN)

We can relate this to the $87 \%$ of NC teachers who valued the support they received from their program mentors. Buzbee Little (2005) suggested that the supportive atmosphere resulting from perceptions of support from peers and mentors led to a sense of belonging for professionals undertaking training. The $1 \mathrm{CN}$ program was certainly designed to include faceto-face sessions because it was accepted that "apprentices learn mostly in relation to other 
apprentices" and that conjoining training and practice is effective because "the circulation of information amongst peers suggests that engagement in practice may well be a condition for the effectiveness of learning" (Lave \& Wenger, 1991, p. 93). Learning about how to deliver the intervention and sharing ideas and practical experiences within a safe space may have facilitated a feeling of belonging to a community of practice by providing opportunities for talking about their work and practicing what they have learnt with each other (Lave \& Wenger, 1991). It is not only in the process of learning about mathematics or how to deliver an intervention, but also in the process of discussing experiences of practice that individuals can be inducted into a particular professional community. These features emerge further in the themes described below.

An opportunity to discuss and share. There were 214 responses that related to the advantages of being able to discuss issues and share experiences with colleagues not only from their own school, but from different schools. The TAs valued the opportunity to discuss issues around their training and its application to the classroom, and felt able to ask questions about aspects of the training in which they were unsure or concerned about. They reported obtaining solutions to solve problems or difficulties they had encountered or anticipated, and they became aware of "potential pitfalls when delivering the sessions". Sharing of successful "strategies to maximize potential benefits of the program" was perceived as beneficial, as did a focus on how to improve. In sum, the discussion time served as a platform to debate their practice, develop self-assurance on what was going well and gain guidance on areas they wanted to further improve, as shown below,

Really useful - sessions allowed us to hear back from other schools and discuss how things were working well (or not so well) (Participant 8, 1CN2)

Chance to evaluate and reflect (Participant 48, 1CN2) 
Great to share tips and strategies with others and to discuss solutions to problems encountered (Participant 163, 1CN2)

This supports previous findings that peer mentoring leads to processes of self-reflection on one's existing practice and professional positioning (Kaunisto et al., 2013). Due to the design of the face-to-face sessions on the $1 \mathrm{CN}$ training, the participants felt encouraged to explicitly identify themselves as members of a "professional learning community" (Lave \& Wenger, 1991), by cultivating some of the strategies they use in practice.

Within this theme, there was a prominent focus on the advantages of gaining new ideas through peer discussions, regarding how to deliver the intervention. Several participants reported, "bouncing ideas off each other". This was evidenced in relation to specific aspects of teaching mathematics (e.g., subtraction), and also extended to sharing ideas about developing teaching and learning techniques and resources, as shown in the quotations below, Have gained so many ideas for how to approach subtraction in the future (Participant $56,1 \mathrm{CN} 2)$

Lovely to hear other people's stories and swap useful ideas re strategies and resources (Participant 224, 1CN)

Able to teach in more simple but effective ways (Participant 290, 1CN) This finding was supported by the quantitative data (Table 1); $96 \%$ of the TAs believed that they had developed their teaching skills and strategies for delivering the intervention during the training, and the qualitative data suggest that they felt that this was due to discussions with colleagues and the sharing of ideas. The findings discussed under this theme bear close resemblance to the perceptions of the teachers undertaking NC in the study by Torgerson et al. (2011). Individuals with different roles (e.g., students, instructors) have been found to hold diverse views about a mentor's role and how it should be enacted (Colvin \& Ashman, 2010), however, the current findings suggest that this does not translate to peer mentoring for 
teachers and TAs. Discussion with colleagues and the benefits that this provides are key components of peer mentoring for TAs, and ones which provide opportunities for developing communities of practice. This extends previous findings (Dunne et al., 2008a, Woolhouse et al., 2009) to TAs undertaking an intervention training program.

In support of the centrality of the specific benefits classified under this theme, the definition of peer mentoring offered by Heikkinen, Jokinen and Tynjala (2012) seems to epitomize them: "Peer-group mentoring is an activity involving teachers sharing and reflecting on their experiences, discussing problems and challenges they meet in their work, listening, encouraging one another, and, above all, learning from each other, and learning together" (p. xv). There is evidence from the comments that the TAs recognize the importance of taking control over their own learning by thinking through how they can translate their new knowledge into their practice in the classroom. They reflect on the "doing" and "being" of becoming intervention practitioners, thus identifying themselves as fully engaged members of a particular professional community. This sense of becoming a particular type of professional can impact upon how individuals feel about their own capabilities, as explored in the next section.

Increased confidence and reassurance. There were 16 explicit claims that the faceto-face sessions and/or peer support aspect had led to increased confidence that they were effectively implementing their training, as illustrated below,

Peer support is excellent it really helps to build confidence and helps you realize you are not the only one with the same issues (Participant $8,1 \mathrm{CN} 2$ )

Reinforcing what I am doing is correct (Participant 291, 1CN) This was supported by the quantitative data (Table 1); $94.4 \%$ of the TAs believed that they had developed their confidence in teaching and supporting mathematics. It also corroborates previous research that has found peer mentoring to increase confidence (Cordingley et al., 
2003; Rhodes \& Beneicke, 2002) and extends the findings to a sample of TAs training on the $1 \mathrm{CN}$ interventions. Relatedly, an emotional dimension of support was acknowledged by participants, in which they referred to feeling "comforted" and reassured that they were "not alone". The quotations below indicate that this support system was particularly beneficial when the TAs were faced with difficulties.

Great to discuss and realize we are not alone and others are facing similar situations both negative and positive (Participant 5, 1CN)

Much easier to discuss problems or ideas within a group with tutor as don't feel so isolated (Participant 249, 1CN2)

The attention to reduced feelings of isolation has been found previously (Buzbee Little, 2005; Kutaka et al., 2017), and may be a key benefit of a sense of belonging for women in particular (Daniell, 2006). The vast majority of participants were female, which mirrors the reality of the school workforce in England. Thomas, Bystydzienski and Desai (2015) argued that peer mentoring may resolve many problems inherent in traditional hierarchical mentoring, representing a more suitable alternative for women working in areas in which they typically encounter more problems than their male counterparts, e.g., in mathematics. This is of particular significance when it is TAs who are undergoing the training. In contrast to teachers, TAs are offered fewer professional development opportunities and are often viewed as having a lower status (Dunne et al., 2008a, 2008b), despite working with children who need more individualized support (Blatchford et al., 2007). Therefore, as has been argued (Reay, David, \& Ball, 2005; Duckworth, 2014), the importance of mentoring and we would argue, particularly of peer mentoring, is the recognition of a colleague's professionalism that can counter the dismissal of some individuals' labor, empowering learners by inviting them to "take agency in directing their educational journey" (Duckworth \& Maxwell, 2015, p. 5). Furthermore, this process can develop a renewed sense of professional collaboration, leading 
to an increase in motivation and enthusiasm for both the subject of mathematics and delivering the intervention, as shown below,

Increased enthusiasm and confidence in maths (Participant 36, 1CN)

Wonderful to see the passion for maths teaching (Participant 56, 1CN2)

Good to hear how the course is for other TAs, good to share, acquire new ideas, to help the children, motivating (Participant 241, 1CN2)

This corroborates previous research (Buzbee Little, 2005; Cordingley et al., 2003; Kutaka et al., 2017; Rhodes \& Beneicke, 2002), suggesting that the increased confidence reported by the TAs induced a sense of empowerment which fuelled their enthusiasm for passing on their training and knowledge to their pupils.

An opportunity to test teaching plans and resources. Twenty-five participants declared that a key benefit of the face-to-face sessions was the opportunity to "try out resources" and "try out lessons practically". Practicing the different games and activities within the group provided the TAs with a safe space to develop their skills, which again increased confidence and prepared them for better practice when delivering the training to the pupils in school. This is illustrated in the quotations below,

By working in a group it's good to try the lessons out first and then you are more confident when delivering them in school (Participant 212, 1CN2)

Being able to discuss different ways of adapting activities and trying out resources before taking them into the classroom (Participant 216, 1CN2)

Discussions regarding the planned activities and games while practicing inherently relates to the "talking about and talking within practice" described by Lave \& Wenger (1991, p. 109). Encouraging individuals to develop subject-specific pedagogy within a professional training context invites them to engage with and reflect upon their membership of a community of 
practice, while also materializing and expressing their professional identity (Kelly et al., 2007; Proweller \& Mitchener, 2004; Settlage, Southerland, Smith, \& Ceglie, 2009).

\section{Towards a Reframed Theory of Peer Mentoring}

Using Lave and Wenger's (1991) research as a theoretical framework to compare the current findings with the existing literature base, we generated a grounded theory which reflects a process of the benefits of the face-to-face sessions and peer mentorship (see Figure 1). This can be used as a starting point to explore the relationships around various benefits of peer mentoring for TAs undertaking intervention training. 


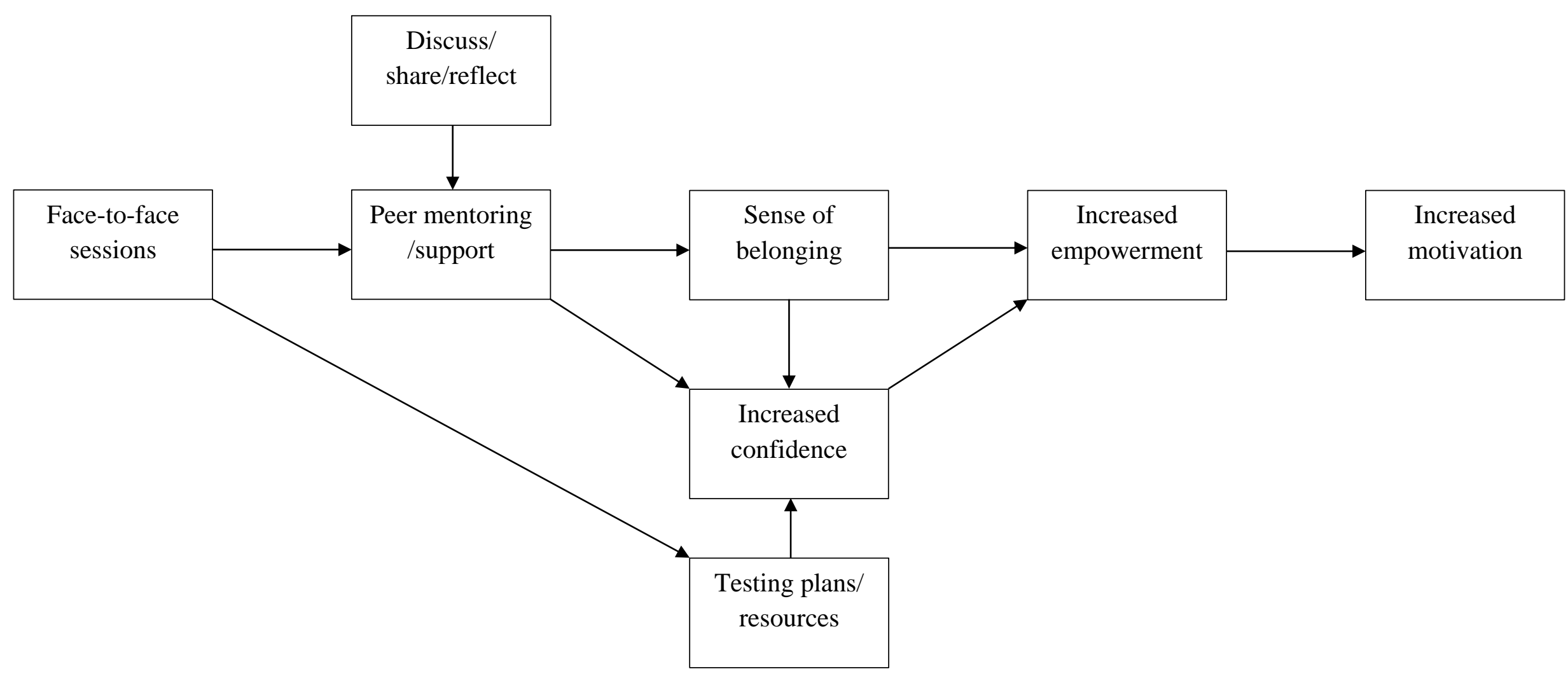

Figure 1. The benefits of peer mentoring amongst TAs undertaking intervention training 
Peer mentoring/support was perceived to be a central aspect of the face-to-face sessions, and for this group of TAs, it was characterized by peer discussions centered on common problems and possible solutions, the sharing of ideas, and self-reflection. Crucially, peer mentoring led to two main advantages: a sense of belonging and increased confidence. Feelings of belonging also induced greater confidence, as did the opportunity to test teaching plans and resources in a safe space, which was provided by the face-to-face sessions. The two key benefits of peer mentoring, belonging and increased confidence, then led to empowerment, which in turn led to augmented motivation for delivering the intervention. According to the TAs, these positive effects were ultimately translated into improved practice in the classroom.

It is interesting to note that the theory bears resemblance to self-determination theory (SDT; Deci, Vallerand, Pelletier, \& Ryan 1991; Ryan \& Deci, 2000), in which it is suggested that individuals have three fundamental psychological needs: the needs for autonomy, which is the need to express oneself and to experience connectedness between one's actions and personal values, relatedness, which refers to the need to feel securely connected to others or to belong to a social group, and competence, which is the need to feel capable of producing desired outcomes and avoiding negative outcomes (Connell \& Wellborn, 1991; Furrer, Skinner, \& Pitzer, 2014). It is further posited in SDT that motivation will be increased when these three needs are perceived to be satisfied (Deci et al., 1991; Ryan \& Deci, 2000). This has been demonstrated empirically in a range of contexts, including teacher motivation (e.g., Carson \& Chase, 2009). Relatedness is conceptually analogous to the sense of belonging that emerged in the present study, and competence is similar to confidence. A sense of belonging was the key component of our reframing of peer mentoring, and it was posited to positively affect confidence. Both factors were proposed to ultimately increase motivation. The crucial role of a sense of relatedness, i.e., belongingness, being the key link to increased motivation, 
even by influencing the other SDT needs, has been reported previously (Nicholson \& Putwain, 2016). Our general questions did not elicit aspects of autonomy from the TAs, indicating that fulfilment of this psychological need was the least salient in the current context.

\section{Conclusion}

We elicited the views of TAs undertaking training on two $1 \mathrm{CN}$ interventions regarding the benefits of face-to-face training sessions and peer mentoring. In general, the participants believed that the training had led to improvements in several areas of their professional development, and that the design of the training sessions had fostered a supportive atmosphere, which was perceived as extremely advantageous and conducive to a range of positive outcomes. Three themes emerged from the analysis, of which we reframed into a theory of peer mentorship benefits, supplemented by the findings of previous studies. We also proposed that group discussions and sharing of ideas, as well as testing and practicing plans and resources, both of which peer mentoring induced, helped the TAs to develop a sense of themselves as specialist mathematics intervention teachers and so identify with this community of practice (Lave \& Wenger, 1991). This again links in with the central concept of belongingness in this study. In addition, Duckworth and Maxwell (2015) recommended, in their social justice model of mentoring, that mentors can "model critical pedagogies and engage in relationships with trainees that are trusting, collaborative and democratic" (p. 15). We would suggest that this is of particular use when peer mentoring is developed as one aspect of a professional development program.

In the theory of peer mentoring generated in this study, we drew together Lave and Wenger's (1991) ideas around community of practice and SDT. The theory is presented as an ongoing work of progress, however, rather than a final conclusion (Holt \& Dunn, 2004). It is important to note that the advantages of peer mentoring were elicited from TAs regarding 
their experience of training sessions only in relation to the $1 \mathrm{CN}$ interventions. Although the positive effects of peer mentoring for establishing a community of practice have been previously reported for TAs undertaking a foundation degree (Dunne et al., 2008a; Woolhouse et al., 2009), there may be different/additional benefits that need to be included in the process for different samples and in different contexts. The present research was initially designed to be an evaluative study of the $1 \mathrm{CN}$ training program, and ethical and time constraints prevented us from inviting busy professionals to provide more extensive feedback on their experiences. The qualitative data which were generated from the open-ended items of the questionnaire can therefore be viewed as a starting point in this body of work. In order to validate our findings, we are currently conducting interviews with TAs undertaking the $1 \mathrm{CN}$ interventions to gather in-depth data that is more ideal for a qualitative/grounded theory approach. An alternative avenue for future research could be to test the relationships proposed by the theory using quantitative methods, however, if based solely on this study, any attempts at theory validation would need to use the same population and context.

The current findings reinforce the importance of peer mentoring for TAs. This was already established for TAs undertaking a foundation degree/further credential in education (Dunne et al., 2008a; Garner et al., 2015; Woolhouse et al., 2009), and has been extended to those embarking on training for a mathematics intervention. A clear implication is to ensure that this aspect remains central to the training of TAs. A possible enhancement to the existing program could be the addition of collaborative teaching, whereby two TAs work in the same classroom and plan, teach and evaluate together (Buzbee Little, 2005). This could occur within a school or across partner schools to share learning more widely. This combination enhances teacher development and student learning as it provides ongoing opportunities for sharing, exploration of new ideas and professional learning (Buzbee Little, 2005). If 
practicalities allow, a guide may be for two TAs to implement their first two $1 \mathrm{CN}$ lessons together, before working alone.

\section{Acknowledgement}

The authors would like to thank Nick Dowrick, the Director of the Every Child Counts programs, for providing detailed information about the $1 \mathrm{CN}$ and $1 \mathrm{CN} 2$ training. 


\section{References}

Blatchford, P., Russell, A., Bassett, P., Brown, P., \& Martin, C. (2007). The role and effects of teaching assistants in English primary schools (Years 4 to 6) 2000-2003. Results from the class size and pupil-adult ratios (CSPAR) KS2 project. British Educational Research Journal, 33(1), 5-26. doi:10.1080/01411920601104292

Blase, J., Hekelman, F. P., \& Rowe, M. (2000). Preceptors' use of reflection to teach in ambulatory settings: an exploratory study. Academic Medicine, 75(9), 947-953.

Buzbee Little, P. (2005). Peer coaching as a support to collaborative teaching. Mentoring \& Tutoring: Partnership in Learning, 13(1), 83-94. doi:10.1080/13611260500040351

Carson, R. L., \& Chase, M. A. (2009). An examination of physical education teacher motivation from a self-determination theoretical framework. Physical Education and Sport Pedagogy, 14(4), 335-353. doi:10.1080/17408980802301866

Chambers, D. (2015). The changing nature of the roles of support staff. In D. Chambers (Vol. Ed.), International Perspectives on Inclusive Education, Volume 4: Working with Teaching Assistants and Other Support Staff for Inclusive Education (pp. 3-25). Bingley, UK: Emerald Group Publishing Limited.

Cheetham, G., \& Chivers, G. (2001). How professionals learn in practice: An investigation of informal learning amongst people working in professions. Journal of European Industrial Training, 25, 248-292

Colvin, J. W., \& Ashman, M. (2010). Roles, risks, and benefits of peer mentoring relationships in higher education. Mentoring \& Tutoring: Partnership in Learning, 18(2), 121-134. doi:10.1080/13611261003678879

Connell, J. P., \& Wellborn, J. G. (1991). Competence, autonomy, and relatedness: A motivational analysis of self-system processes. Minnesota Symposia on Child Psychology, 23, 43-77. 
Cordingley, P. (2005). The role of mentoring and coaching in teachers' learning and development. Education Review, 18(2), 68-74.

Cordingley, P., Bell, M., Rundell, B., \& Evans, D. (2003). The impact of collaborative CPD on classroom teaching and learning: Research evidence in education library. London: EPPI-Centre, Social Science Research Unit, Institute of Education, University of London.

Cox, E. (2012). Individual and organizational trust in a reciprocal peer coaching context. Mentoring \& Tutoring: Partnership in Learning, 20(3), 427-443. doi:10.1080/13611267.2012.701967

Daniell, E. (2006). Every other Thursday. New Haven, CT: Yale University Press.

Deci, E.L., Vallerand, R.J., Pelletier, L.G., \& Ryan. R.M. (1991). Motivation and education the self-determination perspective. Educational Psychologist, 26, 325-346. doi:10.1207/s15326985ep2603and4_6

Department for Education (2015a). National curriculum assessments at key stage 2 in England, 2015 (revisited). Crown copyright.

Department for Education (2015b). Phonics screening check and national curriculum assessments at key stage 1 in England, 2015. Crown copyright.

Department for Education (2016). Statistical first release: School workforce in England: November 2016. Crown copyright.

Department for Education and Skills (2003). Remodeling the Workforce. London: HMSO.

Domitrovich, C.E., Gest, S. D., Gill, S., Bierman, K. L., Welsh, J. A., \& Jones, D. (2009). Fostering high-quality teaching with an enriched curriculum and professional development support: The head start REDI program. American Educational Research Journal, 46(2), 567-597. doi:10.3102/0002831208328089

Dowker, A. (2004). What works for children with mathematical difficulties? Research Report 
554. Department for Education and Skills.

Dowker, A., \& Sigley, G. (2010). Targeted interventions for children with arithmetical difficulties. Understanding Number Development and Difficulties, BJEP Monograph Series II, 7, 65-81.

Dowrick, N. (2015). Numbers Count: A large-scale intervention for young children who struggle with mathematics. In R.C. Kadosh, \& A. Dowker, (Eds.), The Oxford handbook of numerical cognition. Oxford: Oxford University Press.

Duckworth, V. (2014). Literacy and transformation. In V. Duckworth, \& G. Ade-Ojo, (Eds.), Landscapes of specific literacies in contemporary society: Exploring a social model of literacy, Monograph (pp. 27-46). London: Routledge Research in Education.

Duckworth, V., \& Maxwell, B. (2015). Extending the mentor role in initial teacher education: Embracing social justice. International Journal of Mentoring and Coaching in Education, 4(1), 4-20.

Dunne, L., Goddard, G., \& Woolhouse, C. (2008a). Mapping the changes: A critical exploration into the career trajectories of teaching assistants who undertake a foundation degree. Journal of Vocational Education \& Training, 60(1), 49-59.

Dunne, L., Goddard, G., \& Woolhouse, C. (2008b). Teaching assistants perceptions of their Professional role and their experiences of doing a foundation degree. Improving Schools Journal, 11(3), 239-249.

Eraut, M. (1994). Developing professional knowledge and competence. London: Falmer Press.

Every Child a Chance Trust (2010). Every Child a Chance Trust Impact Report 2010. London: Every Child a Chance Trust.

Furrer, C.J., Skinner, E.A., \& Pitzer, J.R. (2014). The influence of teacher and peer 
Relationships on students' classroom engagement and everyday motivational resilience. National Society for the Study of Education, 113, 101-123.

Gardiner, W. (2011). Mentoring in an urban teacher residency: Mentors' perceptions of yearlong placements. The New Educator, 7(2), 153-171.

Garner, P. W., McLean, M. C., Waajid, B., \& Pittman, E. R. (2015). Mentoring and professional development in rural head start classrooms. Mentoring \& Tutoring: Partnership in Learning, 23(4), 293-310. doi:10.1080/13611267.2015.1099868

Heikkinen, H., Tynjälä, P., \& Jokinen, H. (2012). Peer-group mentoring for teacher development. Abingdon: Routledge

Holt, N. L., \& Dunn, J. G. H. (2004). Toward a grounded theory of the psychosocial competencies and environmental conditions associated with soccer success. Journal of Applied Sport Psychology, 16(3), 199-219. doi:10.1080/10413200490437949

Hramiak, A. (2010). Online learning community development with teachers as a means of enhancing initial teacher training. Technology, Pedagogy and Education, 19(1), 47-62. doi:10.1080/14759390903579265

Kaunisto, S. L., Estola, E., \& Leiman, M. (2013). 'I've let myself get tired'-one teacher's self-reflection process in a peer group. Reflective Practice, 14(3), 406-419.

Kaunisto, S.L., Estola, K., \& Niemisto, R. (2012). The group as a context for peer-group mentoring. In H. Heikkinen, H. Jokinen, \& P. Tynjala (Eds.), Peer-group mentoring for teacher development (pp. 112-120). New York, NY: Routledge.

Kelly, P., Gale, K., Wheeler, S., \& Tucker, V. (2007). Taking a stance: promoting deliberate action through online postgraduate professional development. Technology, Pedagogy and Education, 16(2), 153-176. 
Kroll, J. (2017). Requisite participant characteristics for effective peer group mentoring. Mentoring \& Tutoring: Partnership in Learning, 25(1), 78-96. doi:10.1080/13611267.2017.1308096

Kutaka, T. S., Smith, W. M., Albano, A. D., Edwards, C. P., Ren, L., Beattie, H. L., et al. (2017). Connecting teacher professional development and student mathematics Achievement: A 4-year study of an elementary mathematics specialist program. Journal of Teacher Education, 68(2), 140-154. doi:10.1177/0022487116687551

Lave J. \& Wenger E. (1991). Situated learning: Legitimate peripheral participation. New York: Cambridge University Press.

Lincoln, Y. S., and E. G. Guba. 1985. Naturalistic Inquiry. Newbury Park, CA: Sage. Muijs, D., \& Reynolds, D. (2003). The effectiveness of the use of learning support assistants in improving the mathematics achievement of low achieving pupils in primary school. Educational Research, 45(3), 219-230. doi:10.1080/0013188032000137229

Nicholson, L. J. \& Putwain, D. W. (2016). The importance of psychological need satisfaction in educational re-engagement. Research Papers in Education, 1-18. doi: $10.1080 / 02671522.2016 .1271004$

Proweller, A., \& Mitchener, C.P. (2004). Building teacher identity with urban youth: Voices of beginning middle school science teachers in an alternative certification program. Journal of Research in Science Teaching, 41, 1044-1062.

Reay, D., David, M.E. \& Ball, S. (2005). Degrees of choice: Social class, race and gender in Higher Education. Stoke-on-Trent: Trentham Books.

Reid, E. S. (2008). Mentoring peer mentors: Mentor education and support in the composition program. Composition Studies, 36(2), 51-79. 
Rhodes, C., \& Beneicke, S. (2002). Coaching, mentoring and peer-networking: Challenges for the management of teacher professional development in schools. Journal of InService Education, 28(2), 297-310. doi:10.1080/13674580200200184

Ryan, R.M., \& Deci, E.L. (2000). Self-determination theory and the facilitation of intrinsic motivation, social development, and well-being. American Psychologist, 55, 68-78. doi:10.1037/0003-066X.55.1.68

Samson, J. F., Hines, S. J., \& Li, K. (2015). Effective use of paraprofessionals as early intervention reading tutors in grades K-3. Mentoring \& Tutoring: Partnership in Learning, 23(2), 164-177. doi:10.1080/13611267.2015.1049014

Schön, D. A. (1983). The reflective practitioner. Aldershot: Arena.

Schwellnus, H., \& Carnahan, H. (2014). Peer-coaching with health care professionals: What is the current status of the literature and what are the key components necessary in peercoaching? A scoping review. Medical Teacher, 36(1), 38-46.

Settlage, J., S. A. Southerland, L. K. Smith, \& Ceglie, R. (2009). Constructing a doubt-free teaching self: Self-efficacy, teacher identity, and science instruction within diverse settings. Journal of Research in Science Teaching, 46, 102-125.

Strauss, A. L., \& Corbin, J. M. (1998). Basics of qualitative research: Techniques and procedures for developing grounded theory (2nd ed.). Newbury Park, CA: Sage.

Thomas, N., Bystydzienski, J., \& Desai, A. (2015). Changing institutional culture through peer mentoring of women STEM faculty. Innovative Higher Education, 40(2), 143-157. doi:10.1007/s10755-014-9300-9

Torgerson, C., Wiggins, A., Torgerson, D., Ainsworth, H., Barmby, P., Hewitt, C. et al. (2011). Every Child Counts: The independent evaluation report. Department for Education.

Torgerson, C., Wiggins, A., Torgerson, D., Ainsworth, H., \& Hewitt, C. (2013). Every Child 
Counts: Testing policy effectiveness using a randomised controlled trial, designed, conducted and reported to CONSORT standards. Research in Mathematics Education, 15(2), 141-153.

Williams, P. (2008). Independent review of mathematics teaching in early years settings and primary schools. Department for Children, Schools and Families: Crown copyright. Williams, Z. M., \& Grant, A. (2012). How to... Be a good mentor. Education for primary care, 23(1), 56-58.

Woolhouse, C., Dunne, L., \& Goddard, G. (2009). Lifelong learning: Teaching assistants' experiences of economic, social and cultural change following completion of a foundation degree. International Journal of Lifelong Education, 28(6), 763-776.

Zeus, P., \& Skiffington, S. (2002). The coaching at work toolkit: A complete guide to techniques and practices. Sydney: McGraw-Hill. 